\title{
Vitamin D deficiency in patients with intellectual disabilities: prevalence, risk factors and management strategies
}

\author{
Valeria Frighi, Alireza Morovat, Matthew T. Stephenson, Sarah J. White, Christina V. Hammond \\ and Guy M. Goodwin
}

\section{Background}

People with intellectual disabilities have a high risk of osteoporosis and fractures, which could partly be as a result of vitamin D deficiency.

\section{Aims}

To compare the serum vitamin D $(25(\mathrm{OH}) \mathrm{D})$ levels of 155 patients with intellectual disabilities under psychiatric care and 192 controls, investigate potential risk factors for vitamin D deficiency in people with intellectual disabilities and assess available treatments.

\section{Method}

Cross-sectional observational study followed by treatment evaluation.

\section{Results}

Almost twice as many patients with intellectual disabilities had vitamin $D$ deficiency $(25(\mathrm{OH}) \mathrm{D}<50 \mathrm{nmol} / \mathrm{l})$ compared with controls $(77.3 \%$ v. 39.6\%, $P<0.0001)$. In the intellectual disabilities group, winter season $(P<0.0001)$, dark skin pigmentation $(P<0.0001)$, impaired mobility $(P=0.002)$ and obesity $(P=0.001)$ were independently associated with lower serum 25(OH)D. In most patients, $800 \mathrm{IU}$ colecalciferol daily normalised 25(OH)D levels.

\section{Conclusions}

Vitamin D deficiency is highly prevalent in people with intellectual disabilities, partly because of insufficient exposure to sunlight. Screening and treatment strategies, aiming to reduce these patients' high fracture risk, should be introduced. Similar strategies may be required in other psychiatric populations at risk for fractures and with a tendency to spend excessive time indoors.

\section{Declaration of interest}

V.F. and G.M.G. have received grants from the Baily Thomas Charitable Fund. G.M.G. has also received grants from Servier, and speaker honoraria or fees for advice from AstraZeneca, Cephalon/Teva, Eli Lilly, GSK, Lundbeck, Merck, Otsuka, Servier, Takeda and Sunovion.
Vitamin D deficiency is a well-established precursor to osteopenia and osteoporosis and, in the most severe cases, to osteomalacia in adults and rickets in children. Proximal myopathy can accompany the bone changes, leading to a tendency to fall. The potential outcome of these abnormalities is an increased risk of fractures. ${ }^{1}$ Patients with intellectual disabilities in institutions are likely to have reduced exposure to sunlight, ${ }^{2}$ the major determinant of vitamin D production. ${ }^{1}$ Studies in a number of countries looking at institutionalised patients with intellectual disabilities have shown a prevalence of vitamin $\mathrm{D}$ deficiency as defined by serum $25(\mathrm{OH}) \mathrm{D}<50 \mathrm{nmol} / \mathrm{l}$ of between $57 \%$ and $83 \%^{3-5}$ and of $100 \%$ in a sample of patients in whom sunshine exposure was virtually non-existent. ${ }^{6}$ People with intellectual disabilities, particularly those with epilepsy and treated with anti-epileptics, are also known to have a high rate of osteoporosis and fractures. ${ }^{3,7-12}$ This increased risk will be partly related to epilepsy itself, but could also be as a result of vitamin D deficiency because anti-epileptic drugs increase 25-hydroxyvitamin D (25(OH)D) metabolism. However, to our knowledge, no information is available on the vitamin D status of community-living patients with intellectual disabilities and, whether institutionalised or not, no information is available for patients with intellectual disabilities living in the UK. Furthermore, no comparative studies between intellectual disabilities and matched general population controls have been published.

In this paper we report the prevalence of vitamin D deficiency, defined as a serum vitamin $\mathrm{D}[25(\mathrm{OH}) \mathrm{D}]$ of $<50 \mathrm{nmol} / \mathrm{l},{ }^{13,14}$ in a community living group of people with intellectual disabilities under psychiatric care in comparison with a healthy control sample drawn from the same geographical area (Oxfordshire,
UK, latitude $\left.51^{\circ} \mathrm{N}\right)$. We also examine the risk factors for hypovitaminosis $\mathrm{D}$ in people with intellectual disabilities, its potential consequences in terms of low bone mineral density and fractures and evaluate the results of its treatment. The term 'intellectual disabilities' refers to the condition of people with disabilities characterised by significant limitations both in cognitive functioning and adaptive behaviour (conceptual, social and practical adaptive skills) that originate before age 18 years.

\section{Method}

\section{Study population}

The 155 patients with intellectual disabilities presented in this paper were part of the Oxford Learning Disabilities Study. ${ }^{15}$ This was a cross-sectional observational study, approved by the regional ethics committee: all patients aged 18-70 years under the care of the Oxfordshire-based psychiatrists of the Oxfordshire Learning Disability NHS Trust were eligible. Capacity was assessed as outlined in the Mental Capacity Act 2005 Code of Practice. Written informed consent was given by capacitous patients. Those assenting (but formally incapacitous) were only entered into the study after unanimous agreement was obtained from key people in the person with intellectual disabilities' circle of care, (which included one or more carers and/or relatives) that inclusion in the study was in the patient's best interest.

The study investigated the side-effects of antipsychotic treatment as captured primarily by laboratory measures. In all the study patients (the intellectual disabilities group) who agreed 
to give a blood sample, $25(\mathrm{OH}) \mathrm{D}$ was measured because of the widespread use of anti-epileptic medication, which can decrease vitamin D levels, ${ }^{16}$ and because of the clinical history of nonhealing or low trauma fractures in several patients with no obvious risk factors for fractures.

The control group was made up of 192 people from the Oxfordshire general population. These were blood donors from the NHS Blood and Transplant Service of the Oxford University Hospitals NHS Trust, who had given consent for their gender, age and serum 25(OH)D levels to be used for establishing reference laboratory data.

Participants in the intellectual disabilities group were seen in their homes by a study nurse, who took consent, measured height and weight, collected information from carers about their medical and drug history, and took a fasting blood sample for various analytes including $25(\mathrm{OH}) \mathrm{D}$ and calcium. An attempt was also made to quantify the amount of exposure to sunlight and the use of sun protector creams in each individual patient, but the answers obtained from carers did not lead to high-quality, analysable data. Patients with vitamin D deficiency who were deemed by their psychiatrists and carers able to tolerate the procedure without undue distress were referred for measurement of bone mineral density by a dual-energy $\mathrm{x}$-ray absorptiometry (DXA) scan (Hologic).

Patients with normal renal function who had been diagnosed with vitamin $\mathrm{D}$ deficiency in the study and had not yet been given supplements by their general practitioners (GPs) were entered in a good clinical practice initiative. This consisted of offering colecalciferol supplementation according to the clinical algorithm used for the patients with vitamin D deficiency treated at the Metabolic Bone Unit/Oxfordshire Osteoporosis Centre of the Nuffield Orthopaedic Centre (Oxford University Hospitals NHS Trust). The treatment was started following a clinical assessment at the Metabolic Bone Unit and consisted of an oral loading dose of $50000 \mathrm{IU}$ of colecalciferol daily for 3 or 6 days (according to whether baseline serum $25(\mathrm{OH}) \mathrm{D}$ levels were $25-49 \mathrm{nmol} / \mathrm{l}$ or $<25 \mathrm{nmol} / \mathrm{l}$ respectively), followed by monthly $50000 \mathrm{IU}$ as maintenance. Daily calcium supplements were added according to individual patient's intake, assessed with the help of carers, by a nurse-administered questionnaire, and, when possible, by the use of 3-day food diaries. Specifically, patients with a very low calcium intake (less than $500 \mathrm{mg}$ daily) were given the equivalent of $1 \mathrm{~g}$ daily elemental calcium supplements, those with an intermediate intake ( 500 to $<1000 \mathrm{mg}$ ) were given $500 \mathrm{mg}$ daily, and those taking $1 \mathrm{~g}$ or more daily were considered replete and not given any calcium supplements.

As a result of a change in prescription rules, the high-dose vitamin $\mathrm{D}$ preparation used by the specialist service became unavailable to new patients during the course of the good practice initiative. Patients who had been started on the highdose preparation could continue on it, but patients who had not yet been started on supplementation were referred for treatment to their GPs. For the latter patients, supplements mostly consisted of $400 \mathrm{IU}$ of colecalciferol together with $500 \mathrm{mg}$ calcium given twice daily, although five patients were treated with $400 \mathrm{IU}$ colecalciferol daily and another four with various other preparations. Safety of the high-dose intermittent treatment used by the hospital service was evaluated by calcium and $25(\mathrm{OH}) \mathrm{D}$ measurements 1 month after the loading dose. Efficacy of maintenance treatment was evaluated by a $25(\mathrm{OH}) \mathrm{D}$ measurement after a minimum of 3 months from starting either the high-dose intermittent or the low-dose daily treatment.

Available data from the controls were age, gender, $25(\mathrm{OH}) \mathrm{D}$ level and date of blood sampling.

\section{Biochemical analyses}

We measured $25(\mathrm{OH})$ D using a routine in-house liquid chromatography and tandem mass spectrometry method. In 2010, after the release of the National Institute of Standards and Technology's reference material for $25(\mathrm{OH}) \mathrm{D}$, a re-standardised assay was used accordingly. The method specifically measured $25(\mathrm{OH}) \mathrm{D}_{2}$ and $\mathrm{D}_{3}$, and had between-batch coefficients of variation $(\mathrm{CV})$ of $19.0 \%$ and $13.5 \%$ at $25(\mathrm{OH}) \mathrm{D}$ concentrations of 14.5 and $42.8 \mathrm{nmol} / \mathrm{l}$, respectively. The limit of quantification, based on an ability to measure $25(\mathrm{OH}) \mathrm{D}$ with a $\mathrm{CV}$ of $<20 \%$, was taken to be $15 \mathrm{nmol} / \mathrm{l}$. However, in 29 patients the measured $25(\mathrm{OH}) \mathrm{D}$ levels were lower than the limit of quantification, and down to a measured $4.5 \mathrm{nmol} / \mathrm{l}$, where the between-batch $\mathrm{CV}$ of the assay was $26.8 \%$. Calcium was measured by arsenazo III method on an Advia 2400 analyser. The instrument was also used for measuring phosphate by the use of the phosphomolybdate method, as well as the kinetic assay of alkaline phosphatase by the modified diethanolamine-buffered enzymatic method.

\section{Bone mineral density}

Standard definitions of osteopenia and osteoporosis were used for interpretation of the DXA scans. Osteopenia was defined by a T-score of -1.1 to -2.5 (i.e. bone mineral density (BMD) 1.1-2.5 standard deviations below the mean BMD of the normal population at age 30 years) and osteoporosis by a T-score of less than -2.5 (i.e. BMD more than 2.5 standard deviations below the mean BMD of the normal population at age 30 years). Z-scores were also used as they allow comparison with an age- and gender-matched population.

\section{Season}

Normally, around $90 \%$ of the body's vitamin D is produced in the skin from exposure to solar ultraviolet B radiation but at latitudes above $42^{\circ}$, the skin does not make any vitamin $\mathrm{D}$ in the winter months. ${ }^{17}$ Therefore, vitamin D data were segregated according to two seasons with high (Summer: June to November) and low (Winter: December to May) concentrations of 25(OH)D. ${ }^{18}$

\section{Statistical analyses}

Data were analysed using IBM SPSS (version 20) for Windows. As baseline serum $25(\mathrm{OH}) \mathrm{D}$ was not normally distributed, nonparametric tests were used. In the intellectual disabilities and the healthy control groups, baseline $25(\mathrm{OH}) \mathrm{D}$ levels were compared by Mann-Whitney test. Prevalence of vitamin D deficiency in the two groups using different $25(\mathrm{OH}) \mathrm{D}$ cut-off levels was compared by chi-square.

For analyses of the data for individuals in the intellectual disabilities group, the degree of disability was classified as mild or severe, a category which included the diagnostic groups of moderate, severe and profound. This decision was made to avoid analyses of groups with very small number of participants and was based on the rationale that only individuals with mild intellectual disabilities are capable of independent or partly independent living.

In the intellectual disabilities group, median 25(OH)D levels were compared by gender, skin pigmentation (dark $v$. White), mobility (impaired $v$. normal), body mass index (BMI $\geqslant 30 v$. $<30$ ), use of anti-epileptics (on any anti-epileptic $v$. not on anti-epileptics), degree of intellectual disability (mild $v$. severe) using the Mann-Whitney test. A correlation with age was investigated by Spearman correlation coefficient. 
A stepwise linear regression model was used to test for independent associations with $25(\mathrm{OH}) \mathrm{D}$ concentrations, where $\log$ transformed $25(\mathrm{OH}) \mathrm{D}$ was the dependent variable and the above factors were the independent variables. We also compared the $25(\mathrm{OH}) \mathrm{D}$ values of patients with a history of fractures $v$. those without known fractures as a whole group and after the exclusion of patients with obvious causes of fractures (such as highly traumatic falls, long-term untreated hypogonadism).

In the treatment analyses, the rates of normalisation of serum $25(\mathrm{OH}) \mathrm{D}$ to $50 \mathrm{nmo} / \mathrm{l}$ were compared for the high-dose intermittent, the daily $800 \mathrm{IU}$ and the daily $400 \mathrm{IU}$ colecalciferol groups by the Freeman-Halton extension of Fisher's exact test. Mean $25(\mathrm{OH}) \mathrm{D}$ levels were compared for the three groups at baseline and after starting treatment by ANOVA, with addition of the Welch test for equality of means in view of the uneven size of the groups. Changes from baseline within each treatment group were assessed by paired $t$-tests. Differences in the change of serum $25(\mathrm{OH}) \mathrm{D}$ levels between baseline and after starting treatment were compared across the groups by ANOVA, with addition of the Welch test.

Five of the 155 participants with intellectual disabilities (3.2\%) were already on treatment with vitamin $\mathrm{D}$ preparations because of osteoporosis or osteoporotic fractures, when first assessed in the study. These patients were excluded from baseline analyses but their data contributed to treatment evaluation.

\section{Diagnostic thresholds for vitamin D deficiency}

We used a serum concentration of $25(\mathrm{OH}) \mathrm{D}$ of $<50 \mathrm{nmol} / \mathrm{l}$, which is the most widely accepted threshold, because this is the level at which parathyroid hormone secretion starts to increase, promoting bone demineralisation. ${ }^{19}$ We also investigated the prevalence of severe deficiency, defined as serum $25(\mathrm{OH}) \mathrm{D}>30 \mathrm{nmol} / \mathrm{l}$, as this is the level at which osteomalacia can appear. ${ }^{13}$

\section{Results}

\section{Demographics}

The 155 participants in the intellectual disabilities group were aged 42.8 years $($ s.d. $=13.0), 51 \%$ were males and $94 \%$ were of White ethnicity. The 192 participants in the control group were similar to the intellectual disabilities group in age and gender (43.0 years $($ s.d. $=12.2)$, 55\% male). Ethnicity was not formally recorded but it was assumed to reflect that of the general population of Oxfordshire, which is $92 \%$ White.

\section{Characteristics of the intellectual disabilities group}

The degree of intellectual disabilities was mild, moderate, severe and profound in $49.7 \%, 32.3 \%, 14.2 \%$ and $3.9 \%$, respectively. A total of 90 patients $(58 \%)$ had a psychiatric diagnosis with or without challenging behaviour whereas $42 \%$ were under psychiatric care because of challenging behaviour. In total, $40.6 \%$ of the group were on anti-epileptics. The great majority lived in small group homes of two to six patients with their carers, the remaining living independently or with their families.

\section{Vitamin D levels in both groups}

The overall prevalence of vitamin D deficiency was $77.3 \%$ in the intellectual disabilities group and $39.6 \%$ in the control group $(P<0.0001)$, with a wide seasonal variation that was more marked in the control than the intellectual disabilities group. Different cut-offs according to group and season of blood sampling are shown in Table 1.
Median 25(OH)D levels were $28.7 \mathrm{nmol} / \mathrm{l}$ (IQR, 16.9-49.1) for the intellectual disabilities group and $57.9 \mathrm{nmol} / \mathrm{l}$ (IQR, 39.9-77.9) for the control group $(P<0.0001)$. In the participants with vitamin D deficiency, median (IQR) 25(OH)D levels were $22.4 \mathrm{nmol} / \mathrm{l}$ (IQR, 15.2-34.5) and $35.8 \mathrm{nmol} / \mathrm{l}$ (IQR 28.3-49.1) in the intellectual disabilities and the control groups, respectively $(P<0.0001)$. Phosphate and adjusted calcium levels were normal in all patients.

During the summer season, median serum 25(OH)D concentrations for the control and the intellectual disabilities populations were $65.8 \mathrm{nmol} / \mathrm{l}$ (IQR, 51.8-85.1) and $36.7 \mathrm{nmol} / \mathrm{l}$ (IQR, 22.6-53.2), respectively $(P<0.0001)$. During winter, the control and intellectual disabilities groups had median $25(\mathrm{OH}) \mathrm{D}$ levels that were $32.6 \mathrm{nmol} / \mathrm{l}(\mathrm{IQR}, 26.2-41.7)$ and $20.3 \mathrm{nmol} / \mathrm{l}$ (IQR, 13.3-31.2), respectively $(P<0.0001)$, Fig. 1 .

Table 2 shows $25(\mathrm{OH}) \mathrm{D}$ levels in the intellectual disabilities group according to their demographic and clinical characteristics, as well as to season of blood sampling. There was no correlation between serum $25(\mathrm{OH}) \mathrm{D}$ and age and no difference in $25(\mathrm{OH}) \mathrm{D}$ levels between those patients with or without a psychiatric diagnosis.

In linear regression analysis, winter season $(\beta=0.488$, $P<0.0001)$, dark skin pigmentation $(\beta=0.717, \quad P<0.0001)$,

Table 1 Prevalence of vitamin D deficiency by standard cut-off levels in participants not on supplements ${ }^{a}$

\begin{tabular}{|lccc|}
\cline { 2 - 3 } & \multicolumn{3}{c}{$\%$} \\
& $\begin{array}{c}\text { Intellectual } \\
\text { disabilities group } \\
(n=150)\end{array}$ & $\begin{array}{c}\text { Control } \\
\text { group } \\
(n=192)\end{array}$ & $P$ \\
\hline$<50 \mathrm{nmol} / \mathrm{OH})$ & 77.3 & 39.6 & $<0.0001$ \\
\hline Summer & 69.0 & 19.9 & $<0.0001$ \\
\hline Winter & 89.4 & 87.5 & $\mathrm{NS}$ \\
\hline$<30$ nmol/I & 50.0 & 10.9 & $<0.0001$ \\
\hline Summer & 34.5 & 0.7 & $<0.0001$ \\
\hline Winter & 69.7 & 35.7 & $<0.0001$ \\
\hline $\begin{array}{l}\text { a. The overall percentages refer to the whole group irrespective of season. The } \\
\text { percentages by season represent the participants within the relevant 25(OH)D cut-off } \\
\text { as a percentage of the participants tested in that season. }\end{array}$ & \\
\hline
\end{tabular}

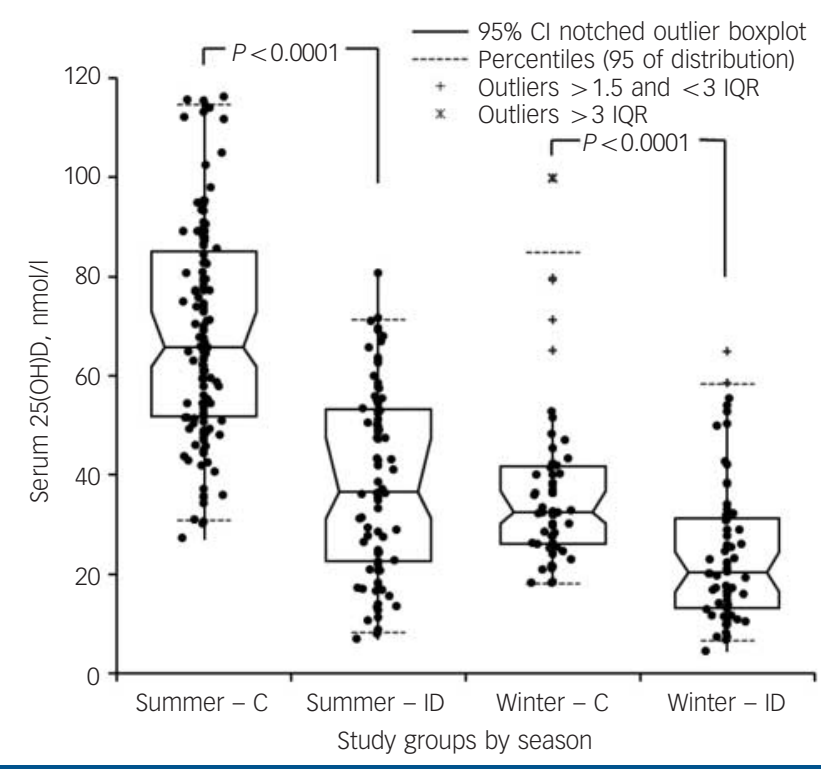

Fig. 1 Serum 25(OH) D concentrations in the control group (C) and the intellectual disabilities group (ID) according to season. 
Table 2 Median (IQR) serum 25(OH)D levels in the intellectual disabilities group not on supplements

\begin{tabular}{|c|c|c|c|}
\hline & $n$ & 25(OH)D, nmol/L: median (IQR) & $P$ \\
\hline Gender & & & 0.348 \\
\hline Males & 77 & $27.6(17.7-50.1)$ & \\
\hline Females & 73 & $28.9(16.4-47.9)$ & \\
\hline Season & & & $<0.0001$ \\
\hline Summer & 84 & $36.7(22.6-53.3)$ & \\
\hline Winter & 66 & $20.3(13.2-31.3)$ & \\
\hline Skin colour & & & 0.002 \\
\hline Dark skin & 9 & $16.3(11.5-17.3)$ & \\
\hline White skin & 141 & $30.8(18.1-49.9)$ & \\
\hline Level of disabilities & & & 0.039 \\
\hline Mild intellectual disabilities & 77 & $34.1(19.4-51.6)$ & \\
\hline Severe intellectual disabilities & 73 & $22.7(16.7-38.3)$ & \\
\hline Body mass index ${ }^{a}$ & & & 0.065 \\
\hline$\geqslant 30$ & 59 & $25.9(15.8-41.2)$ & \\
\hline$<30$ & 73 & $31.7(19.2-53.7)$ & \\
\hline Mobility & & & $<0.0001$ \\
\hline Impaired & 23 & $17.2(10.7-28.9)$ & \\
\hline Normal & 127 & $32.2(18.7-50.3)$ & \\
\hline Medication & & & 0.092 \\
\hline On anti-epileptics & 59 & $24.3(16.5-41.8)$ & \\
\hline Not on anti-epileptics & 91 & $33.0(17.3-52.8)$ & \\
\hline
\end{tabular}

impaired mobility $(\beta=0.530, P=0.002)$ and obesity $(\beta=0.292$, $P=0.001)$ were independently associated with lower $25(\mathrm{OH}) \mathrm{D}$ levels. Together, these factors explained $32 \%$ of the variance.

Answers obtained from carers about patients' exposure to sunlight were too subjective to allow the collection of quantifiable data. On the basis of direct questioning as well as observation, it seemed that the use of sun protector creams was widespread, if not universal, when it was warm and not too cloudy and patients were taken outdoors. Nevertheless, the data collected was anecdotal.

\section{Clinical symptoms of vitamin D deficiency}

Although osteoporosis is asymptomatic until a fracture occurs, an attempt was made to investigate key symptoms of osteomalacia, namely generalised bone pain and proximal muscle weakness. No patient seemed in pain but it was not possible to assess muscle power except in a very small minority of individuals, because of difficulties with cooperation.

\section{Bone mineral density}

In total, 47 patients with vitamin D deficiency (median $25(\mathrm{OH}) \mathrm{D}$ of $22.2 \mathrm{nmol} / \mathrm{l}$ (IQR, 12.6-31.4)), and no evidence of premature hypogonadism, underwent a DXA scan. This showed low bone mineral density at the spine, hip or both in $70.2 \%(n=33)$ of individuals: $31.9 \%(n=15)$ with T-scores less than -2.5 , consistent with osteoporosis and $38.3 \%(n=18)$ with T-scores of -1.1 to -2.5 , consistent with osteopenia. Additionally, the $z$-scores were consistent with the T-scores in $85 \%(n=40)$ of individuals. This signifies that the majority of patients with abnormal DXA scans had decreased bone mineral density not only compared with the normal population at age 30 but also a reference population of their same age and gender. Moreover, although a DXA scan cannot differentiate between osteoporosis and osteomalacia, it is likely that patients with very low T-score may have also had osteomalacic changes. This is corroborated by the finding of raised alkaline phosphatase in $14.3 \% \quad(n=10)$ of the patients with severe vitamin D deficiency $(25(\mathrm{OH}) \mathrm{D}$
$<30 \mathrm{nmol} / \mathrm{l}$ ), and by the subsequent normalisation of the enzyme following colecalciferol treatment.

\section{Fractures}

Twenty participants in the intellectual disabilities group (12.9\% of the whole group) had a history of one or more fractures, as reported by their carers and whenever possible cross-checked on the hospital radiology database. This represented $7.5 \%$ of men and $18.7 \%$ of women $\left(\chi^{2}=4.3, P=0.038\right), 13.1 \%$ of those of White and $10 \%$ of those of non-White ethnicity (not significant). The mean age at fracture was 48.6 years (s.d.=13.6). A history of fractures was more prevalent in patients on anti-epileptics $(20.6 \%$ $(n=13)$ v. $7.6 \%(n=7)$ in patients not on anti-epileptics, $\chi^{2}=6.06$, $P=0.014)$, but there was no difference in the frequency of fractures between patients with normal $25(\mathrm{OH}) \mathrm{D}$ levels or patients with vitamin D deficiency (12\% of patients in each group).

A history of fractures was also analysed, after the exclusion of patients with obvious causes such as catastrophic falls or longterm untreated hypogonadism. This left 13 patients with a positive fracture history. In this analysis, fractures were apparently more frequent in patients with vitamin D deficiency (13 patients had a fracture) than in those with normal serum $25(\mathrm{OH}) \mathrm{D}$ levels (no patients had a fracture) but the difference was not statistically significant $\left(\chi^{2}=3.6, P=0.059\right)$.

\section{Correction of 25(OH)D deficiency}

Of 116 participants in the intellectual disabilities group with serum $25(\mathrm{OH}) \mathrm{D}<50 \mathrm{nmol} / \mathrm{l}, 91 \mathrm{had}$ treatment data available. Of these, 85 individuals had pre- and on-treatment 25(OH)D results, whereas 6 individuals only had $25(\mathrm{OH}) \mathrm{D}$ data while on treatment.

Of the 91 patients with treatment data, 62 were treated by their GPs, 25 by the hospital service, 3 initially by their GPs and subsequently by the hospital service and 1 took an over-the-counter preparation of $200 \mathrm{IU}$ colecalciferol. Of the 65 patients treated by GPs, 57 (88\%) received $800 \mathrm{IU}$ colecalciferol daily, 5 received 
Table 3 Mean serum 25(OH)D concentrations at baseline and after $\geqslant 3$ months of treatment ${ }^{a}$

\begin{tabular}{|c|c|c|c|c|c|}
\hline \multirow[b]{2}{*}{$D_{3}$ supplements } & \multirow[b]{2}{*}{$n$} & \multicolumn{3}{|c|}{ 25(OH)D, nmol/l: mean (s.d.) } & \multirow[b]{2}{*}{$P(\geqslant 3$ months $v$. baseline) } \\
\hline & & Baseline & $\geqslant 3$ months & Delta & \\
\hline High-dose intermittent & 28 & $20.0(10.2)$ & $86.2(18.8)$ & $68.0(22.4)$ & $<0.0001$ \\
\hline 800 IU daily & 57 & $20.9(8.8)$ & $70.5(20.7)$ & $49.7(21.0)$ & $<0.0001$ \\
\hline 400 IU daily & 5 & $26.9(17.2)$ & $41.8(8.7)$ & $14.9(22.1)$ & 0.2 (NS) \\
\hline
\end{tabular}

400 IU daily and another 3 received other oral or injectable $\mathrm{D}_{2}$ or $\mathrm{D}_{3}$ supplements.

Data were compared at baseline and after starting treatment, between the patients taking the high-dose loading and monthly maintenance $\mathrm{D}_{3}$ treatment previously described (high-dose intermittent), the patients taking $800 \mathrm{IU}$ daily and those taking $400 \mathrm{IU} \mathrm{D}_{3}$ daily. Whereas at baseline the $25(\mathrm{OH}) \mathrm{D}$ levels were similar, at follow-up there was a highly significant difference between the three groups, both in the rate of normalisation defined as percentage of patients who reached $25(\mathrm{OH}) \mathrm{D}$ $\geqslant 50 \mathrm{nmol} / 1$ while on treatment, and in the $25(\mathrm{OH}) \mathrm{D}$ levels achieved. The rate of normalisation, was $100 \%(n=28)$ for the high-dose intermittent colecalciferol group, $80.7 \%(n=46)$ for the 800 and $20 \%(n=1)$ for the 400 IU daily colecalciferol group $(P<0.0001)$. There was no difference in age, gender or skin pigmentation between the treatment groups. Table 3 shows the $25(\mathrm{OH}) \mathrm{D}$ levels at baseline and after $\geqslant 3$ months of treatment according to treatment group. There were no cases of treatment emergent hypercalcaemia in any of the groups.

\section{Discussion}

Our study has shown that the prevalence of vitamin D deficiency, as defined by a serum $25(\mathrm{OH}) \mathrm{D}$ level $<50 \mathrm{nmol} / \mathrm{l}$, is markedly higher in the group with intellectual disabilities than in the control group from the general population with similar demographic characteristics living in the same geographical area (Oxfordshire, UK; latitude $51^{\circ} \mathrm{N}$ ). It has also shown that vitamin $\mathrm{D}$ deficiency is more severe in such patients than in individuals from the general population. Moreover, the difference in prevalence between the two groups was far more prominent in summer than in winter. Thus, whereas in winter there was an almost $90 \%$ prevalence of vitamin D deficiency $(25(\mathrm{OH}) \mathrm{D}<50 \mathrm{nmol} / \mathrm{l})$ in both groups, in summer the prevalence was 3.5 times higher in the intellectual disabilities group compared with the control group. Severe vitamin D deficiency $(25(\mathrm{OH}) \mathrm{D}<30 \mathrm{nmol} / \mathrm{l})$, was twice as common in the intellectual disabilities group compared with the control group in winter whereas in summer it was found in over a third of the intellectual disabilities group but in less than $1 \%$ of the control group.

The standard diet contains only minimal quantities of vitamin $\mathrm{D},{ }^{20,21}$ so by far the greatest contribution to the body's vitamin $\mathrm{D}$ levels comes from skin irradiation. Accordingly, insufficient exposure to sunlight is the most likely cause of the difference in the vitamin D levels between the intellectual disabilities group and the control group. Moreover, patients with impaired mobility, who generally need help to go out and may have to cover themselves more than others to maintain body temperature, had vitamin D levels almost 50\% lower than those of patients with normal mobility. This further supports our interpretation of the data.

High prevalence of vitamin D deficiency has been reported in other studies in people with intellectual disabilities. ${ }^{3-6}$ However, to our knowledge this is the first one comparing such patients with the general population and also the first study on community living rather than institutionalised patients with intellectual disabilities.

Our analysis of predictors for vitamin D deficiency in people with intellectual disabilities confirmed well-known risk factors such as winter season, dark skin pigmentation and obesity, as well as impaired mobility. ${ }^{3}$ However, these predictors explained only $32 \%$ of the variance, and other unmeasured factors such as sun exposure, genetic variation ${ }^{22}$ and, to a limited extent, nutrition may play a role.

In particular, the extent of the use of ultraviolet-protection skin creams among patients with intellectual disabilities living in supervised care may be questioned. Such creams decrease the synthesis of vitamin $\mathrm{D},{ }^{23}$ so an excessive use may partly explain the $69 \%$ prevalence of vitamin $\mathrm{D}$ deficiency in the intellectual disabilities population in the summer months. We have no quantitative data to support our hypothesis, but carers regarded protection from sun burn as an important priority for their patients. Realisation of a need to educate carers in the use of sunscreens to allow sufficient production of vitamin D while avoiding sunburn could be a useful outcome from this study.

A previous study in patients with intellectual disabilities had shown no association between vitamin $\mathrm{D}$ deficiency and fractures. ${ }^{3}$ However, hypogonadism, a powerful risk factor for fractures, which is highly prevalent in the intellectual disabilities population (details available from the author on request and also see Jawli et $\mathrm{l}^{24}$ ), was not investigated. Our results, although based on a non-significant trend in a small number of patients, suggest that once other causes, such as catastrophic falls or long-term untreated hypogonadism, have been excluded vitamin D deficiency may play a role in the occurrence of fractures in people with intellectual disabilities. This interpretation is in line with the known causal role of vitamin D deficiency in osteomalacia and osteoporosis. It also accords with the decreased efficacy of bisphosphonates to improve bone mineral density and reduce fracture incidence unless vitamin D deficiency is corrected ${ }^{25}$ and with the clinical requirement that patients be vitamin $\mathrm{D}$ and calcium replete when starting fracture prevention treatment with any of the osteoporosis-specific drugs, which would otherwise be ineffective. ${ }^{26}$ Decreased bone mineral density is a predictor of fractures, so our demonstration of low bone mineral density in $70 \%$ of the vitamin $\mathrm{D}$ deficient patients in whom a DXA was performed, also supports a causal role of vitamin D deficiency in the pathogenesis of fractures in people with intellectual disabilities.

\section{Treatment}

A high-dose intermittent regime, which included a maintenance dose of $50000 \mathrm{IU}$ colecalciferol monthly, achieved the optimal serum $25(\mathrm{OH}) \mathrm{D}$ concentration of $>50 \mathrm{nmol} / \mathrm{l}$ more frequently ( $100 \%$ of the patients) than a daily dose of $800 \mathrm{IU}$ colecalciferol 
daily ( $80 \%$ of the patients). However, in the $20 \%$ of patients treated with $800 \mathrm{IU}$ colecalciferol daily who did not achieve optimal serum vitamin D levels, the mean serum concentration obtained was $43 \mathrm{nmol} / \mathrm{l}$, which is a level for which treatment is not considered mandatory according to UK recommendations. ${ }^{14}$

Given that oral high-dose intermittent colecalciferol treatment regimens in the UK are only available via secondary care and that a standard preparation of $800 \mathrm{IU}$ daily, available through primary care, achieves optimal serum $25(\mathrm{OH}) \mathrm{D}$ concentrations in $80 \%$ of patients, it seems reasonable to opt for the latter preparation in the vast majority of patients. It could also be argued that, as we showed the difference between serum 25(OH)D levels before and after supplementation with colecalciferol to be related to the dose of the supplements, a slightly higher dose than $800 \mathrm{IU}$ daily might be able to normalise $25(\mathrm{OH}) \mathrm{D}$ levels in all patients. Therefore, colecalciferol preparations of $1000 \mathrm{IU}$, which are available over the counter, could also be considered.

A dose of $400 \mathrm{IU}$ colecalciferol daily is the standard dose recommended by the Department of Health for population groups thought to be at risk of vitamin D deficiency, including those who have low or no exposure to the sun. ${ }^{27}$ Our findings, limited admittedly to only five patients, suggest this dose is unlikely to normalise $25(\mathrm{OH}) \mathrm{D}$ levels in people with intellectual disabilities, and that this recommendation requires further scrutiny and should be treated with caution as practical guidance.

\section{Limitations of the study}

Recruitment of patients with intellectual disabilities is challenging, so the sample size remained too small to allow a conclusive analysis of the relationship between vitamin D deficiency and fractures in the intellectual disabilities population. Choice of appropriate controls that reflect population norms is also difficult because volunteers to clinical studies tend to be drawn from more healthy subgroups. Nevertheless, $25(\mathrm{OH}) \mathrm{D}$ levels in our patients were low compared with laboratory values that do reflect the whole population. Finally, the findings apply mostly to people with intellectual disabilities of White ethnic background, as they represented $94 \%$ of our population. Given the association between skin colour and vitamin D deficiency and the limited data we obtained, the problem in many Black and minority ethnic people with intellectual disabilities is likely to be more marked.

\section{Implications of the study}

The results of our study show that vitamin D deficiency is highly prevalent in community-living patients with intellectual disabilities, and that it can be effectively, safely and inexpensively treated. This group should be actively screened for vitamin D deficiency because, although the condition is widespread, treatment of populations with normal vitamin $\mathrm{D}$ levels is unnecessary as it does not improve bone mineral density. ${ }^{28}$ Concomitantly to correction of vitamin D deficiency, calcium intake should also be optimised by dietary improvements or addition of supplements as necessary, which is what we did in our good practice initiative and is recommended by current guidelines. ${ }^{14}$ The benefits that could in theory be gained by a simple intervention such as management of vitamin D deficiency are large, given the human cost of osteoporotic fractures, particularly in patients who are already disabled, and the direct cost of treating these fractures. These have been estimated, for hip fractures, at an average of $£ 12000$ for hospital $\operatorname{costs}^{29}$ and $£ 13000$ in the first 2 years for health and social after care following discharge for those who make a poor recovery. ${ }^{30}$ In populations at high risk of osteoporosis, supplementation with colecalciferol at a median dose of 800 IU daily has been shown to reduce the risk of hip fracture by $30 \% .{ }^{31}$ Our study was not designed, and would have been too small, to investigate an effect of treatment of vitamin $\mathrm{D}$ deficiency on fractures. A large study specifically on fracture prevention with vitamin D normalisation in people with intellectual disabilities is needed, particularly in view of the other factors for bone loss, for example physical inactivity, poor nutrition or hypogonadism, that are common in the intellectual disabilities population.

Our results relate to a special population but they may be relevant to other populations subject to poor health, with clinical or lifestyle characteristics similar to patients with intellectual disabilities. A substantial number of people with severe mental illness, particularly those with psychotic features, may be admitted to hospital or, because of negative symptoms, tend to live indoors. Evidence of vitamin D deficiency in these patients has already been published, ${ }^{32-36}$ and patients with schizophrenia have an increased risk of osteoporosis and fractures. ${ }^{37}$ Whether vitamin $\mathrm{D}$ deficiency should be added to the risk factors for osteoporosis, such as smoking, ${ }^{38}$ alcohol excess, ${ }^{39}$ sedentary lifestyle or hyperprolactinaemic hypogonadism, ${ }^{40,41}$ which are common in people for schizophrenia, seems very likely. As attention switches to the poor general medical outcomes of people with severe mental illness, ${ }^{42}$ a greater awareness of vitamin D deficiency as a measurable and treatable risk factor would be timely.

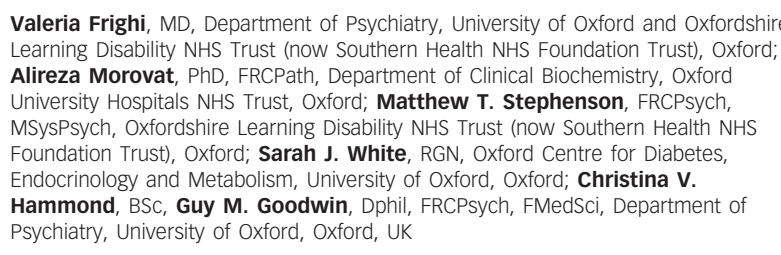

Correspondence: Valeria Frighi, University of Oxford, Department of Psychiatry, Neurosciences Building, Warneford Hospital, Warneford Lane, Oxford OX3 7JX, UK. Email: valeria.frighi@psych.ox.ac.uk

First received 20 Dec 2013, final revision 11 Apr 2014, accepted 30 May 2014

\section{Funding}

Baily Thomas Charitable Fund.

\section{Acknowledgements}

We thank all the patients who participated in the study, the carers for their support, Dr M. Kassim Javaid and Professor John Wass for expert advice and for their role in the good clinical practice initiative, and Mrs Irene Stratton and Dr Marialena Trivella for statistical advice.

\section{References}

1 Holick M F. Vitamin D deficiency. New Engl J Med 2007; 357: 266-81.

2 Vanlint S, Nugent M, Durvasula S. Vitamin D and people with intellectua disability. Aust Fam Physician 2008; 37: 348-51.

3 Vanlint S, Nugent M. Vitamin D and fractures in people with intellectual disability. J Intellect Dis Res 2006; 50: 761-7.

4 Zubillaga P, Garrido A, Mugica I, Ansa J, Zabalza R, Emparanza JI. Effect of vitamin $D$ and calcium supplementation on bone turnover in institutionalized adults with Down's Syndrome. Eur J Clin Nutr 2006; 60: 605-9.

5 Kilpinen-Loisa P, Arvio M, Ilvesmäki V, Mäkitie O. Vitamin D status and optimal supplementation in institutionalized adults with intellectual disability. J Intellect Disabil Res 2009; 53: 1014-23.

6 Wong TS, Lau VM, Lim W, Fung G. A survey of vitamin D level in people with learning disability in long-stay hospital wards in Hong Kong. J Intellect Disabil 2006; 10: 47-59.

7 Srikanth R, Cassidy G, Joiner C, Teeluckdharry S. Osteoporosis in people with intellectual disabilities: a review and a brief study of risk factors for 
osteoporosis in a community sample of people with intellectual disabilities. $J$ Intellect Disabil Res 2011; 55: 53-62

8 Schrager S, Kloss C, Ju, AW. Prevalence of fractures in women with intellectual disabilities: a chart review. J Intellect Disabil Res 2007; 5: 253-9.

9 Tannenbaum TN, Lipworth L, Baker S. Risk of fractures in an intermediate care facility for persons with mental retardation. Am J Ment Retard 1989; 93 444-51.

10 Lohiya GS, Crinella FM, Tan-Figueroa L, Caires S, Lohiya S. Fracture epidemiology and control in a developmental center. West J Med 1999; 170 203-9.

11 Glick NR, Fischer MH, Heisey DM, Leverson GE, Mann DC. Epidemiology of fractures in people with severe and profound developmental disabilities. Osteoporosis Int 2005; 16: 389-96

12 Jancar J, Jancar MP. Age-related fractures in people with intellectual disability and epilepsy. J Intellect Disabil Res 1998; 42: 429-33.

13 Institute of Medicine. Dietary Reference Intakes for Calcium and Vitamin D. National Academy Press, 2010.

14 National Osteoporosis Society. Vitamin $D$ and bone health: a practical clinical guideline for patient management. NOS, 2013 (www.nos.org.uk/ document.doc?id = 1352).

15 Frighi V, Stephenson MT, Morovat A, Jolley IE, Trivella M, Dudley CA, et al. Safety of antipsychotics in people with intellectual disability. Br J Psychiatry 2011; 199: 289-95.

16 Petty SJ, O'Brien TJ, Wark JD. Anti-epileptic medication and bone health. Osteoporosis Int 2007; 18: 129-42.

17 Webb AR, Kline L, Holick MF. Influence of season and latitude on the cutaneous synthesis of vitamin D3: exposure to winter sunlight in Boston and Edmonton will not promote vitamin D3 synthesis in human skin. $J$ Clin Endocrinol Metab 1988; 67: 373-8.

18 Hyppönen E, Power C. Hypovitaminosis D in British adults at age $45 \mathrm{y}$ : nationwide cohort study of dietary and lifestyle predictors. Am J Clin Nutr 2007; 85: 860-8.

19 Bouillon R, Van Schoor NM, Gielen E, Boonen S, Matthieu C, Vanderschueren D, et al. Optimal vitamin D status: a critical analysis on the basis of evidencebased medicine. J Clin Endocrinol Metab 2013; 98: E1283-304.

20 Lawson DE, Paul AA, Black AE, Cole TJ, Mandal AR, Davie M. Relative contributions of diet and sunlight to vitamin $D$ state in the elderly. Br Med J 1979; 2: 303-5.

21 Black L, Walton J, Flynn A, Kiely M. Adequacy of vitamin D intakes in children and teenagers from the base diet, fortified foods and supplements. Public Health Nutr 2014; 17: 721-31.

22 Wang TJ, Zhang F, Richards JB, Kestenbaum B, van Meurs JB, Berry D, et al. Common genetic determinants of vitamin $D$ insufficiency: a genome-wide association study. Lancet 2010; 376: 180-8

23 Faurschou A, Beyer DM, Schmedes A, Bogh MK, Philipsen PA, Wulf HC. The relation between sunscreen layer thickness and vitamin $D$ production after ultraviolet B exposure: a randomized clinical trial. Br J Dermatol 2012; 167 391-5

24 Hawli Y, Nasrallah M, El-Hajj Fuleihan G. Endocrine and musculoskeletal abnormalities in patients with Down syndrome. Nat Rev Endocrinol 2009; 5: $327-34$

25 Adami S, Giannini S, Bianchi G, Sinigaglia L, Di Munno O, Fiore CE, et al. Vitamin $D$ status and response to treatment in post-menopausal osteoporosis. Osteoporosis Int 2009; 20: 239-44
26 National Institute for Health and Care Excellence. Alendronate, Etidronate, Risedronate, Raloxifene, Strontium Ranelate and Teriparatide for the Secondary Prevention of Osteoporotic Fragility Fractures in Postmenopausal Women. NICE, 2008 (http://www.nice.org.uk/nicemedia/live/11748/42508/ 42508.pdf)

27 Chief Medical Officers of England, Wales, Northern Ireland and Scotland. Vitamin D - Advice On Supplements for at Risk Groups. Department of Health, Welsh Government, Department of Health, Social Services and Public Safety and the Scottish Government, 2012 (https://www.gov.uk/government/ uploads/system/uploads/attachment_data/file/213703/dh_132508.pdf).

28 Reid IR, Bolland MJ, Grey A. Effects of vitamin D supplements on bone mineral density: a systematic review and meta-analysis. Lancet 2014; 383 : 146-55.

29 Lawrence TM, White CT, Wenn R, Moran CG. The current hospital costs of treating hip fractures. Injury 2005; 36: 88-91.

30 British Orthopaedic Association. The Care of Patients with Fragility Fractures. The British Orthopaedic Association, 2007 (http://www.nhfd.co.uk/003/ hipfracturer.nsf/luMenuDefinitions/FCEF9FCB98A1B8EB802579C900553996/ \$file/Blue_Book.pdf?OpenElement).

31 Bischoff-Ferrari HA, Willett WC, Orav EJ, Lips P, Meunier PJ, Lyons RA, et al. A pooled analysis of Vitamin $D$ dose requirements for fracture prevention. N Engl J Med 2012; 367: 40-9.

32 Itzhaky D, Amital D, Gorden K, Bogomolni A, Arnson Y, Amital H. Low serum vitamin D concentrations in patients with schizophrenia. Isr Med Assoc J 2012; 14: 88-92.

33 Tiangga E, Gowda A, Dent JA. Vitamin D deficiency in psychiatric in-patients and treatment with daily supplements of calcium and ergocalciferol. Psychiatr Bull 2008; 32: 390-3.

34 Agorastos A, Weinas A, Agorastos AD, Wiedemann K. Psychosis-induced vitamin $D$ deficiency with secondary hyperparathyroidism and osteoporotic fractures. Gen Hosp Psychiatry 2011; 33: 641.e3-5.

35 Gracious BL, Finucane TL, Friedman-Campbell M, Messing S, Parkhurst MN Vitamin D deficiency and psychotic features in mentally ill adolescents: a cross-sectional study. BMC Psychiatry 2012; 12: 38.

36 Crews M, Lally J, Gardner-Sood P, Howes O, Bonaccorso S, Smith S, et al. Vitamin $D$ deficiency in first episode psychosis: a case-control study. Schizophr Res 2013; 150: 533-7.

37 Kishimoto T, De Hert M, Carlson HE, Manu P, Correll CU. Osteoporosis and fracture risk in people with schizophrenia. Curr Opin Psychiatry 2012; 25: 415-29.

38 Yoon V, Maalouf NM, Sakhaee K. The effects of smoking on bone metabolism. Osteoporos Int 2012; 23: 2081-92.

39 Abukhadir SS, Mohamed N, Mohamed N. Pathogenesis of alcohol-induced osteoporosis and its treatment: a review. Curr Drug Targets 2013; 14: 160110.

40 Kishimoto T, Watanabe K, Shimada N, Makita K, Yagi G, Kashima H. Antipsychotic-induced hyperprolactinemia inhibits the hypothalamo-pituitarygonadal axis and reduces bone mineral density in male patients with schizophrenia. J Clin Psychiatry 2008; 69: 385-91.

41 Meaney AM, O'Keane V. Bone mineral density changes over a year in young females with schizophrenia: relationship to medication and endocrine variables. Schizophrenia Res 2007; 93: 136-43.

42 De Hert M, Correll CU, Bobes J, Cetkovich-Bakmas M, Cohen D, Asai I, et al. Physical illness in patients with severe mental disorders. I. Prevalence, impact of medications and disparities in health care. World Psychiatry 2011; 10: $138-51$ 